\title{
Quantification of BRAF V600E alleles predicts papillary thyroid cancer progression
} Min-Hee Kim', Ja Seong Bae'2, Dong-Jun Lim ${ }^{1}$, Hyoungnam Lee ${ }^{3}$, So Ra Jeon
Gyeong Sin Park

${ }^{1}$ Division of Endocrinology and Metabolism, Department of Internal Medicine, ${ }^{2}$ Department of Surgery ${ }^{3}$ Department of Hospital Pathology, ${ }^{4}$ Medical Life Sciences, College of Medicine, The Catholic University of Korea, 222 Banpodaero, Seocho-gu, Seoul 137-701, Republic of Korea
Correspondence should be addressed to $C K$ Jung

Email

ckjung@catholic.ac.kr

\begin{abstract}
The BRAF V600E mutation is the most common genetic alteration in thyroid cancer. However, its clinicopathological significance and clonal mutation frequency remain unclear. To clarify the inconsistent results, we investigated the association between the allelic frequency of $B R A F \mathrm{~V} 600 \mathrm{E}$ and the clinicopathological features of classic papillary thyroid carcinoma (PTC). Tumour tissues from two independent sets of patients with classic PTC were manually microdissected and analysed for the presence or absence of the BRAF mutation and the mutant allelic frequency using quantitative pyrosequencing. For external validation, the Cancer Genome Atlas (TCGA) data were analysed. The BRAF V600E mutation was found in 264 (82.2\%) out of 321 classic PTCs in the training set. The presence of $B R A F$ V600E was only associated with extrathyroidal extension and the absence of thyroiditis. In BRAF V600E-positive tumours, the mutant allelic frequency varied from 8 to $41 \%$ of the total BRAF alleles (median, 20\%) and directly correlated with tumour size and the number of metastatic lymph nodes. Lymph node metastases were more frequent in PTCs with a high ( $\geq 20 \%$ ) abundance of mutant alleles than in those with a low abundance of mutant alleles $(P=0.010)$. These results were reinforced by validation dataset $(n=348)$ analysis but were not reproduced in the TCGA dataset. In a population with prevalent $B R A F$ mutations, quantitative analysis of the $B R A F$ mutation could provide additional information regarding tumour behaviour, which is not reflected by qualitative analysis. Nonetheless, prospective studies are needed before the mutated allele percentage can be considered as a prognostic factor.
\end{abstract}
Key Words
- papillary thyroid carcinoma
- proto-oncogene
- proteins BRAF
mutation

Endocrine-Related Cancer (2014) 21, 891-902

\section{Introduction}

The V600E BRAF mutation is the most common genetic alteration in papillary thyroid carcinoma (PTC). The prevalence of the $B R A F \mathrm{~V} 600 \mathrm{E}$ mutation varies according to the histological subtype; the mutation is frequent in the tall cell variant and classic PTC, but absent in the cribriform-morular variant (Trovisco et al. 2005). The clinical importance of the $B R A F$ mutation derives from its role as a prognostic factor. Recently, mortality 
has been related to BRAF mutation status, which had previously been considered supplemental information to conventional prognostic factors (Xing et al. 2013). Considering the availability of current targeted therapies that include a BRAF inhibitor, the identification of the $B R A F$ mutation may also be a good candidate marker for the prediction of response to targeted therapies. Nevertheless, there remains controversy surrounding the prognostic role of the BRAF mutation, as multiple studies have failed to illustrate a prognostic role for the BRAF mutation (Kim et al. 2005, Cheng et al. 2011, Eloy et al. 2011, Nam et al. 2012, Paulson et al. 2012, Sassolas et al. 2012).

In the studies mentioned above, the BRAF mutation was evaluated in a qualitative manner. The presence of the $B R A F$ mutation in tissues was considered important in the analysis. However, the subclonality of the BRAF mutation in PTCs has recently been suggested (Guerra et al. 2012a). In this context, the quantification of the mutated allele was emphasised in terms of predicting prognosis (Guerra et al. 2012b); however, several studies have shown results contradictory to those findings, as determined by the quantification of mutated alleles (Gandolfi et al. 2013) and immunohistochemical (IHC) staining (Ghossein et al. 2013). The proper value of the quantification of the mutated allele remains in debate and requires further evaluation.

In addition, there is a large variation in the prevalence of the BRAF mutation in PTCs between countries. Generally, the Asian population (especially in Koreans) exhibits up to an $86 \%$ incidence rate for the $B R A F$ mutation compared with a rate that is typically below $60 \%$ in other populations (Chung et al. 2006, Lee et al. 2007, Jung et al. 2010, Xing et al. 2013). In this group, no quantification of mutated allele was evaluated.

Thus, in this study, the implication of quantifying the $B R A F$ mutation will be evaluated in a population in which the mutation is highly prevalent.

\section{Materials and methods}

\section{Patients and specimens}

We retrospectively enrolled two independent sets comprising 670 PTC patients who underwent surgery at Seoul St Mary's Hospital between 2012 and 2014. Classic PTCs were only selected to minimise the bias due to the inclusion of different tumour types. Classic PTCs with tall cell features were excluded. The training set comprised 322 consecutive patients with classic PTC who underwent surgery between February 2012 and January 2013. The independent validation dataset was obtained from a separate cohort of 348 consecutive classic PTC patients (who underwent surgery between February 2013 and December 2013) with the same enrolment criteria. We excluded classic PTCs with marked intratumoural lymphocytic infiltration or densely sclerotic stroma. One representative formalin-fixed and paraffin-embedded tissue block of classic PTCs was selected from each case by a pathologist after reviewing the haematoxylin and eosin-stained slides. In cases with multifocal PTC foci, the largest tumours were chosen for the study. All specimens were collected in accordance with the institutional protocols of our hospital.

\section{Genomic DNA extraction from tumour tissue}

Briefly, paraffin sections of $5-\mu \mathrm{m}$ thickness were heated for $60 \mathrm{~min}$ at $57^{\circ} \mathrm{C}$, deparaffinised in xylene, rehydrated in decreasing concentrations of alcohols and air dried. Tumour areas were manually microdissected under a stereomicroscope to exclude possible contamination by the surrounding normal tissue. Genomic DNA was extracted from the microdissected tumour tissue using the QIAamp DNA FFPE Tissue kit (Qiagen).

\section{PCR}

A 98-bp fragment of exon 15 of the BRAF gene was amplified through PCR using the PyroMark PCR kit (Qiagen). The PCR mixtures included $12.5 \mu$ l of PyroMark PCR Master Mix (Qiagen), $2.5 \mu \mathrm{l}$ of CoralLoad Concentrate (Qiagen), $5 \mu \mathrm{l}$ of Q-solution, $0.5 \mu \mathrm{l}$ of $10 \mu \mathrm{M}$ forward primer (5'-biotin-TTCTTCATGAAGACCTCACAGTAA-3'), $0.5 \mu \mathrm{l}$ of $10 \mu \mathrm{M}$ reverse primer (5'-CCAGACAACTGTTCAAACTGATG-3'), and $4 \mu \mathrm{l}$ of $30 \mathrm{ng} / \mathrm{ul}$ genomic DNA in a final reaction volume of $25 \mu \mathrm{l}$. The PCR conditions were as follows: an initial activation at $95{ }^{\circ} \mathrm{C}$ for $15 \mathrm{~min} ; 42$ cycles of $30 \mathrm{~s}$ at $95{ }^{\circ} \mathrm{C}, 30 \mathrm{~s}$ at $53^{\circ} \mathrm{C}$ and $30 \mathrm{~s}$ at $72{ }^{\circ} \mathrm{C}$ and a final extension at $72^{\circ} \mathrm{C}$ for $10 \mathrm{~min}$. The amplicons were evaluated through $2 \%$ agarose gel electrophoresis.

\section{Pyrosequencing}

After PCR, biotinylated PCR products were immobilised on Streptavidin Sepharose High Performance beads (GE Healthcare, Piscataway, NJ, USA). The reaction mixture for DNA immobilisation consisted of $2 \mu \mathrm{l}$ of Streptavidin Sepharose High Performance beads, $40 \mu$ of PyroMark

Published by Bioscientifica Ltd. 
Binding Buffer (Qiagen), $28 \mu$ l of water (Qiagen), and $10 \mu \mathrm{l}$ of PCR product in a final reaction volume of $80 \mu \mathrm{l}$. Single-stranded DNA for pyrosequencing was prepared on the PyroMark Q24 Vacuum Workstation (Qiagen) according to the manufacturer's instructions. Subsequently, the single-stranded DNA was annealed to the sequencing primer (5'-CCACTCCATCGAGATT- $\left.3^{\prime}\right)$ in a reaction mixture containing $0.8 \mu \mathrm{l}$ of sequencing primer and $24.2 \mu \mathrm{l}$ of PyroMark annealing buffer through a 2-min incubation at $80^{\circ} \mathrm{C}$. The sequencing primer was designed to include an analysis of codons 599-601 of $B R A F$. Pyrosequencing was performed using PyroMark Gold Q24 reagents (Qiagen) on a PyroMark Q24 system (Qiagen), and the data were analysed using the PyroMark Q24 software, version 2.0.6 (Qiagen). The cut-off value was calculated as the mean percentage plus 3s.D.s of the 60 normal controls, plus 3\%. The BRAF mutation status was considered positive if the mutant allele percentage was $8 \%$ or more.

\section{The Cancer Genome Atlas dataset}

For external validation, we investigated 500 thyroid cancer patients from The Cancer Genome Atlas (TCGA) dataset (http://cancergenome.nih.gov/ and http://www. cbioportal.org/); next-generation sequenced DNA mutation data were available for analysis for 400 of these PTC patients. Pathological data were collected from CBioPortal for Cancer Genomics (http://www. cbioportal.org/).

\section{Statistical analysis}

All statistical analyses were performed using the statistical package SPSS (SPSS, Inc.). Categorical variables are presented as the numbers and percentages in the table. Continuous variables are presented as their median and range. For the comparison of categorical parameters, the $\chi^{2}$-test was applied. For comparisons of continuous variables, the Mann-Whitney $U$ tests and $t$-tests were applied for variables without a normal distribution and variables with a normal distribution respectively. The relationship between continuous variables was evaluated using a bivariate correlation. For the multivariate analysis, parameters that showed marginal significance $(P$ values $<0.25)$ were included in a binary logistic regression test.

\section{Results}

\section{Baseline characteristics of the study population}

The patient demographics and clinicopathological features are summarised in Table 1 . In the training set, females comprised $76.1 \%$ of the study population, and the median age at diagnosis was 46 years. All BRAF mutations were the typical $B R A F$ V600E. Based on the cut-off value of $8 \%, B R A F$ V600E was found in $265(82.3 \%)$ out of 322 PTC samples and 188 (83.9\%) out of 224 papillary thyroid microcarcinoma (PTMC) cases, which were defined by a size of $1 \mathrm{~cm}$ or less. There were no significant differences

Table 1 Baseline patient characteristics and clinicopathological features of BRAF mutation-positive and -negative classic papillary thyroid carcinoma in the training and validation sets

\begin{tabular}{|c|c|c|c|c|c|c|c|c|}
\hline & \multicolumn{4}{|c|}{ Training set } & \multicolumn{4}{|c|}{ Validation set } \\
\hline & Patients & $B R A F$ negative & $B R A F$ positive & $P$ value & Patients & $B R A F$ negative & $B R A F$ positive & $P$ value \\
\hline Total & 322 & 57 & 265 & & 348 & 63 & 285 & \\
\hline Females & $245(76.1 \%)$ & $44(77.2 \%)$ & $201(75.8 \%)$ & 0.829 & $277(79.6 \%)$ & $51(81 \%)$ & $226(79.3 \%)$ & 0.768 \\
\hline Age (years) ${ }^{a}$ & $46(13-77)$ & $47(23-77)$ & $46(13-76)$ & 0.554 & $47(17-83)$ & $49(17-75)$ & $46(18-83)$ & 0.627 \\
\hline Tumour size $(\mathrm{mm})^{\mathrm{a}}$ & $7(3-46)$ & $8(3-45)$ & $7(3-46)$ & 0.884 & $6(3-54)$ & $6(3-38)$ & $6(3-54)$ & 0.583 \\
\hline PTMC & $224(69.6 \%)$ & $36(63.2 \%)$ & $188(70.9 \%)$ & 0.247 & $275(79 \%)$ & $51(81.0 \%)$ & $224(78.6 \%)$ & 0.678 \\
\hline Multifocal & $157(48.8 \%)$ & $28(49.1 \%)$ & $129(48.7 \%)$ & 0.952 & $136(39.1 \%)$ & $23(36.5 \%)$ & $113(39.6 \%)$ & 0.644 \\
\hline Extrathyroidal extension & $139(43.2 \%)$ & $16(28.1 \%)$ & $123(46.3 \%)$ & 0.011 & $154(44.1 \%)$ & $20(31.7 \%)$ & $134(47.0 \%)$ & 0.027 \\
\hline pT3-4 stage & $140(43.5 \%)$ & $16(28.1 \%)$ & $124(46.8 \%)$ & 0.010 & $150(43.1 \%)$ & $19(30.2 \%)$ & $131(46.0 \%)$ & 0.022 \\
\hline Lymphatic invasion & $89(27.6 \%)$ & $17(29.8 \%)$ & $72(27.2 \%)$ & 0.684 & $95(27.3 \%)$ & $15(23.8 \%)$ & $80(28.1 \%)$ & 0.492 \\
\hline Vascular invasion & $10(3.1 \%)$ & $3(5.3 \%)$ & $7(2.7 \%)$ & 0.303 & $5(1.4 \%)$ & $1(1.6 \%)$ & $4(1.4 \%)$ & 1.000 \\
\hline Thyroiditis & $87(27.0 \%)$ & $24(42.1 \%)$ & $63(23.8 \%)$ & 0.005 & $105(30.2 \%)$ & $27(42.9 \%)$ & $78(27.4 \%)$ & 0.015 \\
\hline LN metastasis & $161(50.0 \%)$ & $23(41.8 \%)$ & $138(54.1 \%)$ & 0.098 & $179(51.4 \%)$ & $26(41.3 \%)$ & $153(53.7 \%)$ & 0.074 \\
\hline Lateral LN metastasis & $54(16.8 \%)$ & $12(21.8 \%)$ & $42(16.5 \%)$ & 0.343 & $39(11.2 \%)$ & $6(9.5 \%)$ & $33(11.6 \%)$ & 0.640 \\
\hline
\end{tabular}

PTMC, papillary thyroid microcarcinoma $(\leq 1 \mathrm{~cm})$; LN, lymph node. Bold indicates statistical significance, $P<0.05$.

${ }^{a}$ These parameters are presented as the median (range). A Mann-Whitney $U$ test was used for comparison between two groups.

http://erc.endocrinology-journals.org DOI: $10.1530 /$ ERC-14-0147
(C) 2014 Society for Endocrinology Printed in Great Britain
Published by Bioscientifica Ltd. 
Table 2 Distribution of mutated $B R A F$ allele percentages in the papillary thyroid carcinoma

\begin{tabular}{|c|c|c|c|c|c|c|c|c|}
\hline \multirow[b]{2}{*}{ Study } & \multirow{2}{*}{$\begin{array}{l}\text { No. of } \\
\text { cases }\end{array}$} & \multirow[b]{2}{*}{ Histological subtypes } & \multirow{2}{*}{$\begin{array}{c}\text { BRAF } \\
\text { mutation }\end{array}$} & \multicolumn{4}{|c|}{ BRAF V600E allele percentage } & \multirow[b]{2}{*}{ Analysis method } \\
\hline & & & & $\operatorname{Min}(\%)$ & $\operatorname{Max}(\%)$ & Mean $(\%)$ & Median (\%) & \\
\hline $\begin{array}{l}\text { Guerra et al. } \\
\quad(2012 a, b)\end{array}$ & 168 & $\begin{array}{l}\text { Classic }(n=147), \text { follicular } \\
\quad \text { variant }(n=21)\end{array}$ & $90(53.6 \%)$ & 5.1 & 44.7 & 21.9 & 20.6 & Pyrosequencing \\
\hline $\begin{array}{l}\text { Gandolfi et al. } \\
\text { (2013) }\end{array}$ & 132 & $\begin{array}{l}\text { Classic }(n=64) \text {, tall cell variant } \\
(n=38), \text { follicular variant } \\
(n=21) \text {, diffuse sclerosing } \\
(n=2) \text {, solid }(n=2), \\
\text { microcarcinoma }(n=5)\end{array}$ & $58(43.9 \%)$ & 7.5 & 49.8 & 27.4 & NA & Pyrosequencing \\
\hline $\begin{array}{l}\text { Nikiforova } \\
\text { et al. (2013) }\end{array}$ & 57 & $\begin{array}{l}\text { Classic }(n=27) \\
\quad \text { follicular variant }(n=30)\end{array}$ & $21(36 \%)$ & 18.0 & 44.0 & 34.0 & NA & NGS \\
\hline $\begin{array}{l}\text { de Biase et al. } \\
\text { (2014) }\end{array}$ & 155 & $\begin{array}{l}85 \text { BRAF V600E-positive } \\
\text { tumours: classic }(n=45), \\
\text { follicular variant }(n=15), \\
\text { tall cell variant }(n=25)\end{array}$ & $85(54.8 \%)$ & 2 & 53.6 & 33.8 & 32.5 & $\begin{array}{l}\text { Allele-specific } \\
\text { locked nucleic } \\
\text { acid PCR }\end{array}$ \\
\hline TCGA & 400 & $\begin{array}{l}\text { All subtypes }{ }^{\mathrm{a}} \\
\text { Classic }(n=108) \\
\text { With thyroiditis }(n=45)\end{array}$ & $\begin{array}{c}247(61.8 \%)^{b} \\
83(76.9 \%) \\
32(71 \%)\end{array}$ & $\begin{array}{r}4 \\
4 \\
14\end{array}$ & $\begin{array}{l}57 \\
54 \\
51\end{array}$ & $\begin{array}{l}33.6 \\
35.1 \\
31.7\end{array}$ & $\begin{array}{l}35 \\
36 \\
34\end{array}$ & NGS \\
\hline Present study & & & & & & & & \\
\hline Training set & 322 & $\begin{array}{l}\text { Classic }(n=322) \\
\text { With thyroiditis }(n=87) \\
\text { Without thyroiditis }(n=235)\end{array}$ & $\begin{array}{r}265(82.3 \%) \\
63(72.4 \%) \\
202(86.0 \%)\end{array}$ & $\begin{array}{l}8 \\
8 \\
8\end{array}$ & $\begin{array}{l}41 \\
36 \\
41\end{array}$ & $\begin{array}{l}20.3 \\
16.2 \\
21.6\end{array}$ & $\begin{array}{l}20 \\
15 \\
21\end{array}$ & Pyrosequencing \\
\hline Validation set & 348 & $\begin{array}{l}\text { Classic }(n=348) \\
\text { With thyroiditis }(n=105) \\
\text { Without thyroiditis }(n=243)\end{array}$ & $\begin{array}{r}285(81.9 \%) \\
78(74.3 \%) \\
207(85.2 \%)\end{array}$ & $\begin{array}{l}8 \\
8 \\
8\end{array}$ & $\begin{array}{l}42 \\
34 \\
42\end{array}$ & $\begin{array}{l}20.2 \\
17.1 \\
21.4\end{array}$ & $\begin{array}{l}20 \\
15 \\
22\end{array}$ & \\
\hline
\end{tabular}

TCGA, The Cancer Genome Atlas (http://cancergenome.nih.gov/); NGS, next-generation sequencing; NA, not assessed

${ }^{a}$ Classic $(n=108)$, classic with tall cell features $(n=10)$, follicular $(n=115)$, tall cell $(n=25)$, oncocytic $(n=8)$, diffuse sclerosing $(n=2)$, columnar cell $(n=2)$, microcarcinoma $(n=2)$, Warthin-like $(n=2)$, Cribriform $(n=2)$ variants, and NA $(n=124)$.

${ }^{b}$ Out of 247 papillary carcinomas with BRAF mutation, $245(99.2 \%)$ have BRAF V600E mutation and two have BRAF fusion mutation.

in the baseline characteristics between the training and validation sets.

\section{Approach to the status of BRAF mutation by conventional methods (whether positive or negative)}

There was no association between $B R A F$ mutational status and either age at diagnosis, tumour size or multifocality in the training and validation sets. The presence of extrathyroidal extension, a higher incidence of pT3-4 and the absence of chronic lymphocytic thyroiditis were significantly associated with $B R A F$ in two independent sets (Table 1).

\section{Distribution of mutated $B R A F$ allele percentage}

In only the BRAF-positive tumours, the median for the frequency of allele mutation was 20\% (range 8-41\%) and $20 \%$ (range $8-42 \%$ ), respectively, in the training and validation sets. PTCs with thyroiditis had a lower percentage of the mutated allele than those without thyroiditis. We compared our results with previously published data and the results obtained from the
TCGA dataset. A detailed distribution of the allele mutation percentages is summarised in Table 2. Studies using next-generation sequencing (NGS) technology for BRAF mutation identification showed higher mutant allele percentages than those using pyrosequencing.

\section{Impact of BRAF V600E allele percentage on clinicopathological features}

When the study population was categorised into $B R A F$ mutation negative (mutated allele frequency $<8 \%$ ) and low allele-mutation (allele frequency 8-19\%) and high allele-mutation (allele frequency $\geq 20 \%$ ) groups (based on the cut-off value derived from the median value of studied subjects), there was no significant difference in the clinicopathological features between the negative and low allele-mutation groups in two independent sets (Tables 3 and 4). However, the high allele-mutation group had a larger tumour size and a higher incidence of extrathyroidal extension, pT3-4 and lymph node metastasis than the negative and low allele-mutation groups (Table 3). These results were also consistent with those from the validation and total sets (Tables 4 and 5).

Published by Bioscientifica Ltd. 
Table 3 Comparison of clinicopathological features according to the percentage of mutated BRAF alleles in the training set $(n=322)$

\begin{tabular}{|c|c|c|c|c|c|}
\hline & Negative (A) $(n=57)$ & Low $(\mathrm{B})(n=128)$ & High $(C)(n=137)$ & Comparison group & $P$ value \\
\hline Allele frequency ${ }^{a}$ & & $15 \%(8-19)$ & $25 \%(20-41)$ & & \\
\hline \multirow[t]{3}{*}{ Females } & $44(77.2 \%)$ & $97(76.4 \%)$ & $104(7.59 \%)$ & $A$ vs $B$ & 0.835 \\
\hline & & & & A vs $C$ & 0.849 \\
\hline & & & & $B$ vs $C$ & 0.980 \\
\hline \multirow[t]{3}{*}{ Age (years) ${ }^{a}$} & $47(23-77)$ & $47(21-75)$ & $42(13-76)$ & $A$ vs $B$ & 0.963 \\
\hline & & & & $A$ vs $C$ & 0.270 \\
\hline & & & & $B$ vs $C$ & 0.173 \\
\hline \multirow[t]{3}{*}{ Tumour size $(\mathrm{mm})^{\mathrm{a}}$} & $8(3-45)$ & $6(3-40)$ & $8(3-46)$ & $A$ vs $B$ & 0.057 \\
\hline & & & & $A$ vs $C$ & 0.126 \\
\hline & & & & $B$ vs $C$ & $<0.001$ \\
\hline \multirow[t]{3}{*}{ Multifocality } & $28(49.1 \%)$ & $67(52.3 \%)$ & $62(45.3 \%)$ & $A$ vs $B$ & 0.686 \\
\hline & & & & A vs $C$ & 0.623 \\
\hline & & & & $B$ vs $C$ & 0.249 \\
\hline \multirow[t]{3}{*}{ Extrathyroidal extension } & $16(28.1 \%)$ & $47(36.7 \%)$ & $76(55.5 \%)$ & $A$ vs $B$ & 0.252 \\
\hline & & & & A vs $C$ & $<0.001$ \\
\hline & & & & B vs C & 0.002 \\
\hline \multirow[t]{3}{*}{ pT3-4 stage } & $16(28.1 \%)$ & $47(36.7 \%)$ & $77(56.2 \%)$ & $A$ vs $B$ & 0.252 \\
\hline & & & & $A$ vs $C$ & $<0.001$ \\
\hline & & & & B vs $C$ & 0.001 \\
\hline \multirow[t]{3}{*}{ Lymphatic invasion } & $17(29.8 \%)$ & $28(21.9 \%)$ & $44(32.1 \%)$ & $A$ vs $B$ & 0.245 \\
\hline & & & & $A$ vs $C$ & 0.754 \\
\hline & & & & B vs $C$ & 0.061 \\
\hline \multirow[t]{3}{*}{ Vascular invasion } & $3(0.5 \%)$ & $1(0.1 \%)$ & $6(4.4 \%)$ & $A$ vs $B$ & 0.088 \\
\hline & & & & $A$ vs $C$ & 0.725 \\
\hline & & & & B vs $C$ & 0.121 \\
\hline \multirow[t]{3}{*}{ Thyroiditis } & $24(42.1 \%)$ & $47(36.7 \%)$ & $16(11.7 \%)$ & $A$ vs $B$ & 0.487 \\
\hline & & & & A vs $C$ & $<0.001$ \\
\hline & & & & B vs C & $<0.001$ \\
\hline \multirow[t]{3}{*}{ LN metastasis } & $23(40.4 \%)$ & $58(45.3 \%)$ & $80(58.4 \%)$ & $A$ vs $B$ & 0.530 \\
\hline & & & & A vs C & 0.022 \\
\hline & & & & B vs $C$ & 0.010 \\
\hline \multirow[t]{3}{*}{ Lateral LN metastasis } & $13(22.8 \%)$ & $15(11.7 \%)$ & $28(20.4 \%)$ & $A$ vs $B$ & 0.052 \\
\hline & & & & $A$ vs $C$ & 0.713 \\
\hline & & & & $B$ vs $C$ & 0.054 \\
\hline \multirow[t]{3}{*}{ Number of metastatic LN $^{a}$} & $0(0-35)$ & $0(0-22)$ & $1(0-41)$ & $A$ vs $B$ & 0.820 \\
\hline & & & & $A$ vs $C$ & 0.055 \\
\hline & & & & B vs C & 0.003 \\
\hline
\end{tabular}

LN, lymph node; negative, $<8 \%$; low, 8-19\%; high, 20-50\%. Bold indicates statistical significance, $P<0.05$.

${ }^{a}$ These parameters are presented as the median (range). A Mann-Whitney $U$ test was used for comparison between two groups.

\section{Correlation between mutated allele frequency and tumour progression}

Among the tumours with the BRAF V600E mutation, the frequency of mutated alleles directly correlated with the tumour size $(P<0.001$, Fig. $1 \mathrm{a}$ and $P<0.001$, Fig. $1 \mathrm{~b}$ respectively) and the number of metastatic lymph nodes ( $P<0.001$, Fig. $2 \mathrm{a}$ and $P<0.001$, Fig. $2 \mathrm{~b}$ respectively) in the training and validation sets. After the exclusion of PTMC, the association between the size of the tumours $\left(R^{2}=0.141, P=0.001\right.$ and $R^{2}=0.125, P=0.005$ respectively) or the number of metastatic lymph nodes $\left(R^{2}=0.083, P=0.012\right.$ and $R^{2}=0.020, P=0.272$ respectively) with the percentage of mutated alleles remained significant in the training and validation sets. Excluding the population with concomitant chronic lymphocytic thyroiditis, the size of the tumour $\left(R^{2}=0.219, P<0.001\right.$ and $R^{2}=0.163, P<0.001$ respectively) or the number of lymph node metastases $\left(R^{2}=0.070, P<0.001\right.$ and $R^{2}=0.042, P=0.003$ respectively) was significantly related to the percentage of mutated alleles in the training and validation sets.

\section{Qualitative and quantitative determination of BRAF mutational status in PTMC}

There was a significant relationship between $B R A F$ mutational status and extrathyroidal extension and the absence of chronic lymphocytic thyroiditis in PTMCs of

Published by Bioscientifica Ltd 
Table 4 Comparison of clinicopathological features among three study groups according to the percentage of mutated $B R A F$ alleles in the validation set $(n=348)$

\begin{tabular}{|c|c|c|c|c|c|}
\hline & Negative (A) $(n=63)$ & Low $(B)(n=135)$ & High $(C)(n=150)$ & Comparison group & $P$ value \\
\hline Allele frequency ${ }^{a}$ & & $13(8-19)$ & $26(20-42)$ & & \\
\hline \multirow{3}{*}{ Females } & $51(81.0 \%)$ & $113(83.7 \%)$ & $113(75.3 \%)$ & $A$ vs $B$ & 0.633 \\
\hline & & & & $A$ vs $C$ & 0.374 \\
\hline & & & & B vs C & 0.082 \\
\hline \multirow[t]{3}{*}{ Age (years) ${ }^{a}$} & $49(17-75)$ & $48(18-75)$ & $44(18-83)$ & $A$ vs $B$ & 0.688 \\
\hline & & & & $A$ vs $C$ & 0.221 \\
\hline & & & & B vs C & 0.036 \\
\hline \multirow[t]{3}{*}{ Tumour size $(\mathrm{mm})^{\mathrm{a}}$} & $6(3-38)$ & $5(3-40)$ & $7(3-54)$ & $A$ vs $B$ & 0.119 \\
\hline & & & & A vs $C$ & 0.017 \\
\hline & & & & B vs C & $<0.001$ \\
\hline \multirow[t]{3}{*}{ Multifocality } & $23(36.5 \%)$ & $46(34.1 \%)$ & $67(44.7 \%)$ & $A$ vs $B$ & 0.738 \\
\hline & & & & $A$ vs $C$ & 0.271 \\
\hline & & & & B vs C & 0.068 \\
\hline \multirow[t]{3}{*}{ Extrathyroidal extension } & $20(31.7 \%)$ & $53(39.3 \%)$ & $81(54.0 \%)$ & $A$ vs $B$ & 0.307 \\
\hline & & & & A vs $C$ & 0.003 \\
\hline & & & & B vs $C$ & 0.013 \\
\hline \multirow[t]{3}{*}{ pT3-4 stage } & $19(30.2 \%)$ & $51(37.8 \%)$ & $80(53.3 \%)$ & $A$ vs $B$ & 0.296 \\
\hline & & & & A vs $C$ & 0.002 \\
\hline & & & & B vs $C$ & 0.009 \\
\hline \multirow[t]{3}{*}{ Lymphatic invasion } & $15(23.8 \%)$ & $32(23.7 \%)$ & $48(32 \%)$ & $A$ vs $B$ & 0.987 \\
\hline & & & & $A$ vs $C$ & 0.232 \\
\hline & & & & B vs $C$ & 0.120 \\
\hline \multirow[t]{3}{*}{ Vascular invasion } & $1(1.6 \%)$ & $0(0 \%)$ & $4(2.7 \%)$ & $A$ vs $B$ & 0.318 \\
\hline & & & & $A$ vs $C$ & 1.000 \\
\hline & & & & B vs $C$ & 0.124 \\
\hline \multirow[t]{3}{*}{ Thyroiditis } & $27(42.9 \%)$ & $49(36.3 \%)$ & $29(19.3 \%)$ & $A$ vs $B$ & 0.377 \\
\hline & & & & A vs $C$ & $<0.001$ \\
\hline & & & & B vs C & 0.001 \\
\hline \multirow[t]{3}{*}{ LN metastasis } & $26(41.3 \%)$ & $64(47.4 \%)$ & $89(59.3 \%)$ & $A$ vs $B$ & 0.419 \\
\hline & & & & A vs $C$ & 0.016 \\
\hline & & & & B vs $C$ & 0.044 \\
\hline \multirow[t]{3}{*}{ Lateral LN metastasis } & $6(9.5 \%)$ & $14(10.4 \%)$ & $19(12.7 \%)$ & $A$ vs $B$ & 0.854 \\
\hline & & & & $A$ vs $C$ & 0.515 \\
\hline & & & & B vs $C$ & 0.545 \\
\hline \multirow[t]{3}{*}{ Number of metastatic LN $^{a}$} & $0(0-21)$ & $0(0-29)$ & $1(0-23)$ & $A$ vs $B$ & 0.685 \\
\hline & & & & $A$ vs $C$ & 0.025 \\
\hline & & & & B vs $C$ & 0.009 \\
\hline
\end{tabular}

LN, lymph node; negative, $<8 \%$; low, 8-19\%; high, 20-50\%. Bold indicates statistical significance, $P<0.05$.

${ }^{a}$ These parameters are presented as the median (range). A Mann-Whitney $U$ test was used for comparison between two groups.

the training set (Supplementary Table 1, see section on supplementary data given at the end of this article). Among the PTMCs with BRAF mutation, the high allelemutation group was significantly associated with a larger tumour size as well as the presence of extrathyroidal extension and the absence of thyroiditis (Supplementary Table 2). However, there was no significant relationship between the mutated allele percentages and lymph node metastasis (Supplementary Table 2).

\section{Multivariate analysis of lymph node metastasis prediction}

In the univariate analysis, lymph node metastasis was significantly associated with the size of the tumour, patient age, a high percentage of a mutated allele, tumour multifocality, extrathyroidal extension and lymphatic invasion. However, in the multivariate analysis, the significance of multifocality and the percentage of mutated alleles were lost in the training and validation sets (Table 6).

\section{TCGA validation set}

Of the 400 PTC patients available for DNA sequencing data in TCGA, we selected only 108 patients with classic PTC to analyse the relationship between pathological features and BRAF mutation status (Table 7). BRAF positivity was correlated with the presence of extrathyroidal extension $(P=0.001)$ and pT3-4 stage $(P=0.007)$ but not with other factors. We further categorised 81 patients with $B R A F$

Published by Bioscientifica Ltd. 
Table 5 Comparison of clinicopathological features among three study groups according to the percentage of mutated $B R A F$ alleles in the total set $(n=670)$

\begin{tabular}{|c|c|c|c|c|c|}
\hline & Negative (A) $(n=120)$ & Low $(B)(n=263)$ & High $(C)(n=287)$ & Comparison group & $P$ value \\
\hline Allele frequency ${ }^{a}$ & & $14(8-19)$ & $26(20-42)$ & & \\
\hline \multirow{3}{*}{ Females } & $95(79.2 \%)$ & $210(79.8 \%)$ & $217(75.6 \%)$ & $A$ vs $B$ & 0.878 \\
\hline & & & & $A$ vs $C$ & 0.439 \\
\hline & & & & B vs C & 0.233 \\
\hline \multirow[t]{3}{*}{ Age (years) ${ }^{a}$} & $47(17-77)$ & $48(18-75)$ & $43(13-83)$ & $A$ vs $B$ & 0.748 \\
\hline & & & & $A$ vs $C$ & 0.093 \\
\hline & & & & B vs C & 0.013 \\
\hline \multirow[t]{3}{*}{ Tumour size $(\mathrm{mm})^{\mathrm{a}}$} & $7(3-45)$ & $6(3-40)$ & $8(3-54)$ & $A$ vs $B$ & 0.015 \\
\hline & & & & A vs $C$ & 0.007 \\
\hline & & & & B vs C & $<0.001$ \\
\hline \multirow[t]{3}{*}{ Multifocality } & $51(42.5 \%)$ & $113(43.0 \%)$ & $129(44.9 \%)$ & $A$ vs $B$ & 0.932 \\
\hline & & & & $A$ vs $C$ & 0.650 \\
\hline & & & & B vs C & 0.640 \\
\hline \multirow[t]{3}{*}{ Extrathyroidal extension } & $36(30 \%)$ & $100(38.0 \%)$ & $157(54.7 \%)$ & $A$ vs $B$ & 0.128 \\
\hline & & & & A vs $C$ & $<0.001$ \\
\hline & & & & B vs $C$ & $<0.001$ \\
\hline \multirow[t]{3}{*}{ pT3-4 stage } & $35(29.2 \%)$ & $98(37.3 \%)$ & $157(54.7 \%)$ & $A$ vs $B$ & 0.123 \\
\hline & & & & A vs $C$ & $<0.001$ \\
\hline & & & & B vs $C$ & $<0.001$ \\
\hline \multirow[t]{3}{*}{ Lymphatic invasion } & $32(26.7 \%)$ & $60(22.8 \%)$ & $92(32.1 \%)$ & $A$ vs $B$ & 0.413 \\
\hline & & & & $A$ vs $C$ & 0.281 \\
\hline & & & & B vs $C$ & 0.015 \\
\hline \multirow[t]{3}{*}{ Vascular invasion } & $4(3.3 \%)$ & $1(0.4 \%)$ & $10(3.5 \%)$ & $A$ vs $B$ & 0.035 \\
\hline & & & & $A$ vs $C$ & 1.000 \\
\hline & & & & B vs $C$ & 0.009 \\
\hline \multirow[t]{3}{*}{ Thyroiditis } & $51(42.5 \%)$ & $96(36.5 \%)$ & $45(15.7 \%)$ & $A$ vs $B$ & 0.263 \\
\hline & & & & A vs $C$ & $<0.001$ \\
\hline & & & & B vs C & $<0.001$ \\
\hline \multirow[t]{3}{*}{ LN metastasis } & $49(40.8 \%)$ & $122(46.4 \%)$ & $169(58.9 \%)$ & $A$ vs $B$ & 0.310 \\
\hline & & & & A vs $C$ & 0.001 \\
\hline & & & & B vs $C$ & 0.003 \\
\hline \multirow[t]{3}{*}{ Lateral LN metastasis } & $18(15 \%)$ & $28(10.6 \%)$ & $47(16.4 \%)$ & $A$ vs $B$ & 0.188 \\
\hline & & & & $A$ vs $C$ & 0.892 \\
\hline & & & & B vs $C$ & 0.069 \\
\hline \multirow[t]{3}{*}{ Number of metastatic LN $^{a}$} & $0(0-35)$ & $0(0-29)$ & $1(0-41)$ & $A$ vs $B$ & 0.876 \\
\hline & & & & A vs $C$ & 0.003 \\
\hline & & & & B vs $C$ & $<0.001$ \\
\hline
\end{tabular}

LN, lymph node; negative, $<8 \%$; low, 8-19\%; high, 20-50\%. Bold indicates statistical significance, $P<0.05$.

${ }^{a}$ These parameters are presented as the median (range). A Mann-Whitney $U$ test was used for comparison between two groups.

V600E into low allele-mutation (allele frequency 4-35\%) and high allele-mutation (allele frequency $\geq 36 \%$ ) groups (based on the cut-off value derived from the median value of studied subjects). In the semi-quantitative analysis, the increase in mutated allele frequency was significantly associated with extrathyroidal extension and high pT stage. However, there was no correlation between the frequency of mutated alleles and tumour size or lymph node metastases.

\section{Discussion}

In this study, we evaluated the clinical implication of a quantitative approach of describing $B R A F$ mutations (the percentage of mutated alleles) in a population with

http://erc.endocrinology-journals.org DOI: 10.1530/ERC-14-0147
(C) 2014 Society for Endocrinology Printed in Great Britain a high $B R A F$ mutation prevalence. We found that the quantitative analysis of $B R A F$ mutation provided additional information regarding tumour behaviour that was not reflected by a qualitative analysis in both the training and validation sets. In addition, a substantial portion of PTC cases showed intratumoural heterogeneity in terms of the BRAF mutation.

In our training set, $82.3 \%$ of the population conventionally showed the $B R A F$ mutation, which is consistent with previous Korean studies (Chung et al. 2006, Kim et al. 2009, Jung et al. 2010). The BRAF positivity rate appears to be higher in our study than in other studies performing a quantitative analysis of $B R A F$ mutations (Guerra et al. 2012a,b, Gandolfi et al. 2013). As the incidence of $B R A F$ mutation in PTCs varies 

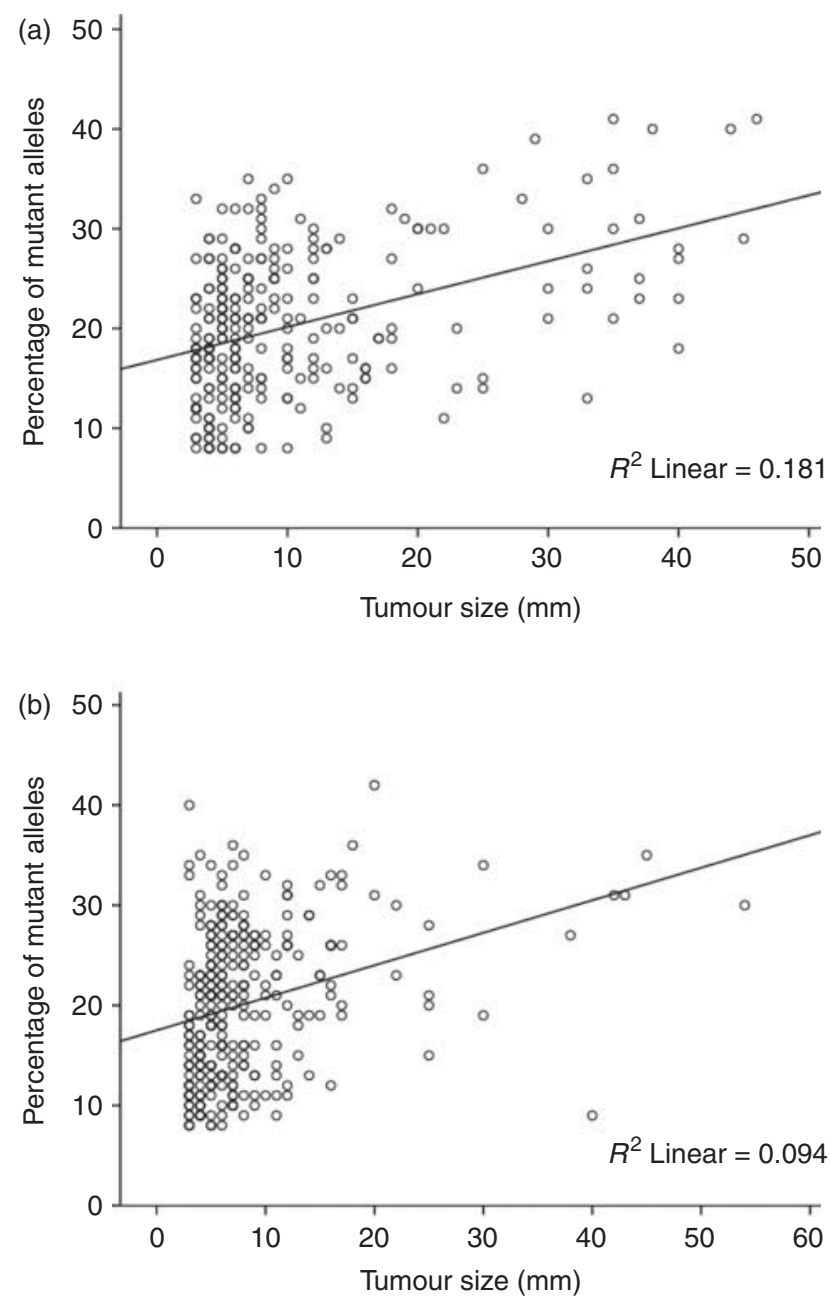

Figure 1

Association between the percentage of mutant alleles of BRAF V600E and tumour size in the training (a) and validation (b) sets.

depending on the histological subtype, such a difference in $B R A F$ mutation positivity might derive from the histological subtypes included in the analysis. Previous studies have included follicular variants of PTC as well as classic variants, but we only selected classic PTCs and excluded any other histological subtype such as follicular variant, tall cell variant and classic PTCs with tall cell features. This may partly explain the lower incidence of $B R A F$ mutations in western populations. In the TCGA dataset, the mutation rate was $76.9 \%$ for classic PTCs and $61.8 \%$ for all PTCs.

Using a conventional approach, there was no significant association of BRAF positivity with clinical/ pathological parameters other than the presence of extrathyroidal extension and the absence of thyroiditis. The association of BRAF mutation with the presence of extrathyroidal extension and the absence of thyroiditis (Kim et al. 2012, Nam et al. 2012) and the absence of thyroiditis (Sargent et al. 2006, Kim et al. 2009) was concordant with previous studies. By contrast, taking a quantitative approach to describe the BRAF-positive population revealed that groups with a high percentage of allelic mutation were closely related to poor prognostic parameters (such as tumour size, extrathyroidal extension, lymph node metastasis and the number of metastatic lymph nodes) compared with low mutation-percentage groups. A low percentage of allelic mutation was related to a high incidence of thyroiditis. PTCs with a low BRAF mutation-percentage had a clinical behaviour similar to that of $B R A F$-negative tumours. It is possible that there was a high prevalence of patients with a low percentage of mutant alleles in previous studies that described a lack of a relationship between $B R A F$ positivity and unfavourable
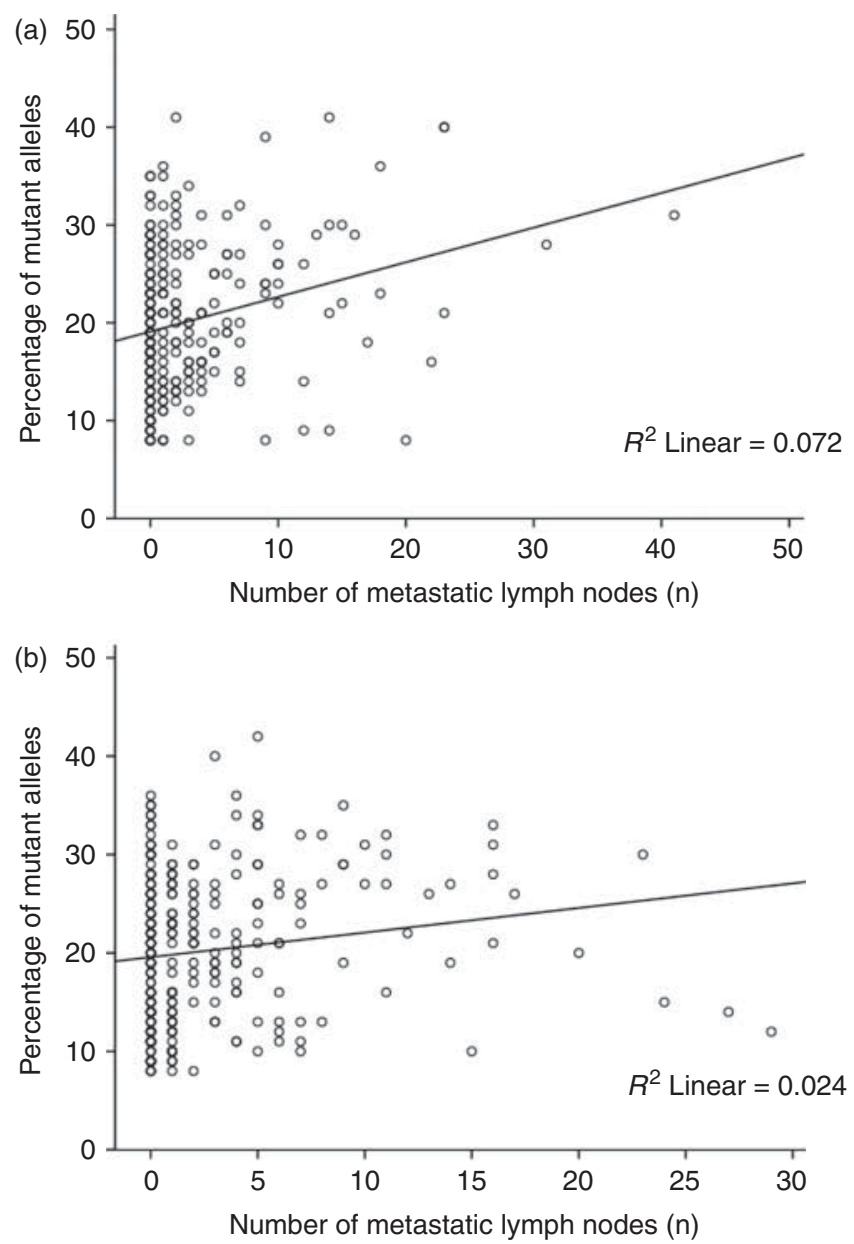

Figure 2

Association between the percentage of mutant alleles of BRAF V600E and the number of metastatic lymph nodes in the training (a) and validation (b) sets.

Published by Bioscientifica Ltd. 
Table 6 Multivariate logistic regression analysis for predicting lymph node metastasis in the training and validation sets of patients with classic papillary thyroid carcinoma

\begin{tabular}{|c|c|c|c|c|c|c|}
\hline \multirow[b]{2}{*}{ Parameters } & \multicolumn{3}{|c|}{ Training set } & \multicolumn{3}{|c|}{ Validation set } \\
\hline & $\mathrm{HR}$ & $95 \% \mathrm{Cl}$ & $P$-value & $\mathrm{HR}$ & $95 \% \mathrm{Cl}$ & $P$-value \\
\hline Tumour size & 1.052 & $1.013-1.093$ & 0.009 & 1.099 & $1.041-1.160$ & 0.001 \\
\hline Age above 60 & 0.972 & $0.950-0.995$ & 0.018 & 0.950 & $0.929-0.971$ & $<0.001$ \\
\hline $\begin{array}{l}\text { High frequency of } B R A F \\
\text { V600E allele }\end{array}$ & 1.251 & $0.712-2.197$ & 0.437 & 1.064 & $0.634-1.786$ & 0.815 \\
\hline Multifocality & 1.464 & $0.843-2.543$ & 0.175 & 1.890 & 1.119-3.191 & 0.017 \\
\hline Extrathyroidal extension & 2.770 & $1.541-4.978$ & 0.001 & 2.244 & $1.312-3.839$ & 0.003 \\
\hline Lymphatic invasion & 8.647 & 3.933-19.008 & $<0.001$ & 3.620 & 1.907-6.872 & $<0.001$ \\
\hline
\end{tabular}

$H R$, hazard ratio. Bold indicates statistical significance, $P<0.05$.

parameters. Analysis of the percentage of mutated alleles in a population with prevalent $B R A F$ mutations may provide clues to explain the discordant role of $B R A F$ mutations in determining patient prognosis.

Intratumoural heterogeneity has been recognised since Nowell (1976) suggested that tumour heterogeneity could be acquired during progression. Several methods have been applied to detect intratumoural heterogeneity such as IHC staining, fluorescence in situ hybridisation, microarray analysis or DNA sequencing. In various cancers, intratumoural heterogeneity has already been demonstrated and has been related to patient prognosis or treatment response (Taniguchi et al. 2008, Gerlinger et al. 2012, Seol et al. 2012, Anaka et al. 2013). In our study, the $B R A F$ mutation status was also found to be heterogeneous via quantitative pyrosequencing. Recently, the efficacy of several tyrosine kinase inhibitors, especially those targeting BRAF kinase activity, has been investigated in refractory thyroid carcinomas. The quantification of the intratumoural heterogeneity of $B R A F$ mutations would be useful to predict the response to such therapies.

The correlation between the percentage of allele mutation and the tumour size appears significant in terms of evaluating the role of the $B R A F$ mutation in carcinogenesis. As suggested by the heterogeneity of RET/PTC rearrangements in post-Chernobyl PTCs (Unger et al. 2004), the heterogeneity of the BRAF mutation in PTCs could be caused by $B R A F$ mutation development in tumour initiation with a later emergence of clones without mutation or by selection for cells harbouring the $B R A F$ mutation during tumour progression. Considering the relationship between the percentage of mutated alleles and tumour size, the latter hypothesis based on the clonal evolution theory (Nowell 1976) appears plausible. This hypothesis is supported by several studies that analysed the status of the $B R A F$ mutation in both primary lesions and metastases (Oler et al. 2005, Vasko et al. 2005). However, the issue of BRAF mutational heterogeneity and clonal evolution in thyroid cancer is

Table 7 Relationship between clinicopathological features and BRAF mutation status in 108 classic papillary thyroid carcinomas from TCGA dataset

\begin{tabular}{|c|c|c|c|c|c|c|c|c|c|}
\hline & \multicolumn{4}{|c|}{ BRAF positivity } & \multicolumn{5}{|c|}{ BRAF V600E allele frequency } \\
\hline & Patients & $\begin{array}{c}B R A F \\
\text { negative }\end{array}$ & $\begin{array}{c}\text { BRAF } \\
\text { positive }\end{array}$ & $\begin{array}{c}P \\
\text { value }\end{array}$ & Patients & $\begin{array}{c}\text { Negative } \\
(<4 \%)\end{array}$ & $\begin{array}{c}\text { Low } \\
(4-36 \%)\end{array}$ & $\begin{array}{c}\text { High } \\
(\geq 36 \%)\end{array}$ & $\begin{array}{c}P \\
\text { value }\end{array}$ \\
\hline Total & 108 & $25(23.1 \%)$ & $83(76.9 \%)^{a}$ & & 106 & $25(23.6 \%)$ & $38(35.8 \%)$ & $43(40.6 \%)$ & \\
\hline Tumour size $(\mathrm{mm})^{\mathrm{b}}$ & $20(7-82)$ & $17(7-55)$ & $20(10-82)$ & 0.245 & $20(7-82)$ & $17(7-55)$ & $19(11-50)$ & $25(10-82)$ & 0.122 \\
\hline Multifocal & $63 / 107(58.9 \%)$ & $14(22 \%)$ & $49(78 \%)$ & 0.738 & $62 / 105(59.0 \%)$ & $14(23 \%)$ & $20(32 \%)$ & $28(45 \%)$ & 0.417 \\
\hline $\begin{array}{l}\text { Extrathyroidal } \\
\text { extension }\end{array}$ & $32 / 108(29.6 \%)$ & $1(3 \%)$ & $31(97 \%)$ & 0.001 & $31 / 106(29.2 \%)$ & $1(3 \%)$ & $13(42 \%)$ & $17(55 \%)$ & 0.006 \\
\hline pT3-4 stage & $37 / 108$ & $3(8 \%)$ & $34(92 \%)$ & 0.007 & $36 / 106(34 \%)$ & $3(8 \%)$ & $12(33 \%)$ & $21(58 \%)$ & 0.008 \\
\hline LN metastasis & $57 / 92(62 \%)$ & $16(28 \%)$ & $41(72 \%)$ & 0.805 & $55 / 90(61 \%)$ & $16(29 \%)$ & $18(33 \%)$ & $21(38 \%)$ & 0.781 \\
\hline $\begin{array}{l}\text { Lateral LN } \\
\text { metastasis }\end{array}$ & $26 / 92(28 \%)$ & $8(31 \%)$ & $18(69 \%)$ & 0.627 & $25 / 90(28 \%)$ & $8(32 \%)$ & $8(32 \%)$ & $9(36 \%)$ & 0.840 \\
\hline Thyroiditis & $45 / 107(42.1 \%)$ & $13(29 \%)$ & $32(71 \%)$ & 0.250 & $45 / 105(43 \%)$ & $13(29 \%)$ & $20(44 \%)$ & $12(27 \%)$ & 0.054 \\
\hline
\end{tabular}

LN, lymph node. Bold indicates statistical significance, $P<0.05$.

${ }^{a}$ Out of 83 classic papillary carcinomas with BRAF mutation, $81(98 \%)$ have BRAF V600E mutation and two have $B R A F$ fusion mutation.

${ }^{\mathrm{b}}$ These parameters are presented as the median (range). A Mann-Whitney $U$ test was used for comparison between two groups.

http://erc.endocrinology-journals.org DOI: 10.1530/ERC-14-0147
(C) 2014 Society for Endocrinology Printed in Great Britain
Published by Bioscientifica Ltd. 
still controversial. Ricarte-Filho et al. (2009) found $100 \%$ concordance of BRAF mutational status between the primary thyroid cancers and the related metastatic sites.

In our study, the quantification of the mutated allele was evaluated using pyrosequencing. We observed that $\sim 30 \%$ of PTCs with BRAF V600E had more than $25 \%$ of the mutated allele. These results are comparable to those obtained in the pyrosequencing study by Guerra et al. $(2012 a, b)$. However, these pyrosequencing data are in contrast to the results achieved using NGS and IHC staining. Nikiforova et al. (2013) evaluated BRAF mutated alleles using NGS and reported that $80 \%$ of PTCs with $B R A F \mathrm{~V} 600 \mathrm{E}$ had more than $25 \%$ of the mutated alleles. In the TCGA dataset, $86 \%$ of classic PTCs with BRAF V600E had more than $25 \%$ of the mutated alleles. In studies using a mutation-specific antibody against the BRAF V600E protein, the immunostaining pattern was homogenous in most PTCs, supporting the BRAF mutation as a clonal event (Bullock et al. 2012, Koperek et al. 2012, Ghossein et al. 2013). Recently, de Biase et al. (2014) have found the heterogeneous distribution of BRAF V600E within the PTC using both immunohistochemistry and quantitative DNA analytical methods. They also revealed the correspondence between mutated allele percentage and the extent and distribution of the BRAF V600E immunoreactivity in a subset of PTCs. However, there is still a puzzling discrepancy between the proportion of BRAF V600Eimmunoreactive cells and mutant allele percentage based on DNA analysis in the study by de Biase et al. We are not sure as to why pyrosequencing underestimated the fraction of alleles carrying BRAF V600E compared with NGS. The clonal evolution theory is also contradictory to the previous belief that the $B R A F$ mutation is an initial event in thyroid carcinoma carcinogenesis, which was supported by experimental methods (Knauf et al. 2005).

Considering that $69.6 \%$ (in training set) and $79.0 \%$ (in validation set) of the studied population were PTMC, it may be interesting to evaluate the possibility of the $B R A F$ mutated allele percentage in PTMC as a biomarker for tumour aggressiveness. A high BRAF mutated allele percentage was related to tumour size, extrathyroidal extension and the absence of thyroiditis but not with lymph node metastasis. Therefore, the utility of $B R A F$ mutation quantitative analysis in PTMC as a progression marker is not yet justified.

As there were many PTMCs in the current study, there may be some concern that contamination by normal tissue surrounding the tumour cells could be responsible for the results. In the presence of thyroiditis in particular, contamination of tumour cells by lymphoid cells should be considered, as mentioned in a previous study (Marotta et al. 2013). To prevent the underestimation of mutated allele percentages by the contamination of non-tumour cells, careful microdissection was performed and tumours with marked lymphocytic infiltration were excluded in our study. The exclusion of PTMC or PTC with thyroiditis did not alter the association between the mutated allele percentages and tumour size. Although the association of the mutated allele percentage with the number of lymph nodes lost significance after the exclusion of PTMC, a significant association was still maintained after the exclusion of PTC with thyroiditis. Recently, a normalisation method has been introduced by de Biase et al. (2014) to overcome the problem of normal cell contamination. They normalised the frequency of mutated alleles to the real amount of tumour cells within each PTC sample. Most samples showed an increase in the percentage of mutated allele after normalisation. Thus, the inevitable contamination of non-tumoural cells still remained as fundamental weakness of the current study.

As this study did not have a follow-up period sufficient to estimate patient prognosis, the prognostic implications of a high percentage of $B R A F$ mutation are limited. In addition, the same methodology should be evaluated in fine-needle aspiration samples, which could help with PTC patient management before surgery. If similar results are obtained, surgical decisions could be made based on the quantitative approach in cytology samples. However, as quantitative analysis of cytology samples may differ from that of tissue microdissection, this requires further evaluation in a future study. We used an arbitrary cut-off of $20 \%$ based on the median value for risk stratification. It may be arguable whether our results can be generalised. Although the mutated allele percentage was found to be a predictor of lymph node metastases in the univariate analysis, this relationship lost significance in the multivariate analysis. In the TCGA validation dataset, we did not find any relationship between the mutated allele percentage and lymph node metastasis or tumour size. Thus, prospective studies are needed before the mutated allele percentage can be considered to be a prognostic factor for predicting lymph node metastasis.

In conclusion, an allelic mutation rate high above the median value is associated with PTC aggressiveness in terms of tumour size and the number of lymph node metastases. Therefore, quantitative analysis of the BRAF mutation in mutation-prevalent populations may provide accurate characteristics of tumour behaviour among $B R A F$-positive PTCs.

Published by Bioscientifica Ltd. 


\section{Supplementary data}

This is linked to the online version of the paper at http://dx.doi.org/10.1530/ ERC-14-0147.

\section{Declaration of interest}

The authors declare that there is no conflict of interest that could be perceived as prejudicing the impartiality of the research reported.

\section{Funding}

This research was supported by the Basic Science Research Program through the National Research Foundation of Korea (NRF) funded by the Ministry of Science, ICT and future planning (2013R1A2A2A01068570); and Catholic Medical Center Research Foundation made in the programme year of 2013.

\section{References}

Anaka M, Hudson C, Lo PH, Do H, Caballero OL, Davis ID, Dobrovic A, Cebon J \& Behren A 2013 Intratumoral genetic heterogeneity in metastatic melanoma is accompanied by variation in malignant behaviors. BMC Medical Genomics 6 40. (doi:10.1186/1755-8794-6-40)

de Biase D, Cesari V, Visani M, Casadei GP, Cremonini N, Gandolfi G, Sancisi V, Ragazzi M, Pession A, Ciarrocchi A et al. 2014 High-sensitivity BRAF mutation analysis: BRAF V600E is acquired early during tumor development but is heterogeneously distributed in a subset of papillary thyroid carcinomas. Journal of Clinical Endocrinology and Metabolism 99 E1530-E1538. (doi:10.1210/jc.2013-4389)

Bullock M, O’Neill C, Chou A, Clarkson A, Dodds T, Toon C, Sywak M, Sidhu SB, Delbridge LW, Robinson BG et al. 2012 Utilization of a MAB for BRAF(V600E) detection in papillary thyroid carcinoma. Endocrine-Related Cancer 19 779-784. (doi:10.1530/ERC-12-0239)

Cheng S, Serra S, Mercado M, Ezzat S \& Asa SL 2011 A high-throughput proteomic approach provides distinct signatures for thyroid cancer behavior. Clinical Cancer Research 17 2385-2394 (doi:10.1158/10780432.CCR-10-2837)

Chung KW, Yang SK, Lee GK, Kim EY, Kwon S, Lee SH, Park do J, Lee HS Cho BY, Lee ES et al. 2006 Detection of BRAFV600E mutation on fine needle aspiration specimens of thyroid nodule refines cyto-pathology diagnosis, especially in BRAF600E mutation-prevalent area. Clinical Endocrinology 65 660-666. (doi:10.1111/j.1365-2265.2006.02646.x)

Eloy C, Santos J, Soares P \& Sobrinho-Simoes M 2011 The preeminence of growth pattern and invasiveness and the limited influence of BRAF and RAS mutations in the occurrence of papillary thyroid carcinoma lymph node metastases. Virchows Archiv 459 265-276. (doi:10.1007/s00428011-1133-7)

Gandolfi G, Sancisi V, Torricelli F, Ragazzi M, Frasoldati A, Piana S \& Ciarrocchi A 2013 Allele percentage of the BRAF V600E mutation in papillary thyroid carcinomas and corresponding lymph node metastases: no evidence for a role in tumor progression. Journal of Clinical Endocrinology and Metabolism 98 E934-E942. (doi:10.1210/ jc.2012-3930)

Gerlinger M, Rowan AJ, Horswell S, Larkin J, Endesfelder D, Gronroos E, Martinez P, Matthews N, Stewart A, Tarpey P et al. 2012 Intratumor heterogeneity and branched evolution revealed by multiregion sequencing. New England Journal of Medicine 366 883-892. (doi:10.1056/NEJMoa1113205)

Ghossein RA, Katabi N \& Fagin JA 2013 Immunohistochemical detection of mutated BRAF V600E supports the clonal origin of BRAF-induced thyroid cancers along the spectrum of disease progression. Journal of

http://erc.endocrinology-journals.org DOI: 10.1530/ERC-14-0147
(C) 2014 Society for Endocrinology Printed in Great Britain
Clinical Endocrinology and Metabolism 98 E1414-E1421. (doi:10.1210/ jc.2013-1408)

Guerra A, Sapio MR, Marotta V, Campanile E, Rossi S, Forno I, Fugazzola L, Budillon A, Moccia T, Fenzi G et al. 2012a The primary occurrence of BRAF(V600E) is a rare clonal event in papillary thyroid carcinoma. Journal of Clinical Endocrinology and Metabolism 97 517-524. (doi:10.1210/jc.2011-0618)

Guerra A, Fugazzola L, Marotta V, Cirillo M, Rossi S, Cirello V, Forno I, Moccia T, Budillon A \& Vitale M 2012b A high percentage of BRAFV600E alleles in papillary thyroid carcinoma predicts a poorer outcome. Journal of Clinical Endocrinology and Metabolism 97 2333-2340. (doi:10.1210/jc.2011-3106)

Jung CK, Kang YG, Bae JS, Lim DJ, Choi YJ \& Lee KY 2010 Unique patterns of tumor growth related with the risk of lymph node metastasis in papillary thyroid carcinoma. Modern Pathology 23 1201-1208. (doi:10.1038/modpathol.2010.116)

Kim TY, Kim WB, Song JY, Rhee YS, Gong G, Cho YM, Kim SY, Kim SC, Hong SJ \& Shong YK 2005 The BRAF mutation is not associated with poor prognostic factors in Korean patients with conventional papillary thyroid microcarcinoma. Clinical Endocrinology 63 588-593. (doi:10.1111/j.1365-2265.2005.02389.x)

Kim SK, Song KH, Lim SD, Lim YC, Yoo YB, Kim JS \& Hwang TS 2009 Clinical and pathological features and the BRAF(V600E) mutation in patients with papillary thyroid carcinoma with and without concurrent Hashimoto thyroiditis. Thyroid 19 137-141. (doi:10.1089/thy.2008. 0144)

Kim TH, Park YJ, Lim JA, Ahn HY, Lee EK, Lee YJ, Kim KW, Hahn SK, Youn YK, Kim KH et al. 2012 The association of the BRAF(V600E) mutation with prognostic factors and poor clinical outcome in papillary thyroid cancer: a meta-analysis. Cancer 118 1764-1773. (doi:10.1002/cncr.26500)

Knauf JA, Ma X, Smith EP, Zhang L, Mitsutake N, Liao XH, Refetoff S, Nikiforov YE \& Fagin JA 2005 Targeted expression of BRAFV600E in thyroid cells of transgenic mice results in papillary thyroid cancers that undergo dedifferentiation. Cancer Research 65 4238-4245. (doi:10.1158/0008-5472.CAN-05-0047)

Koperek O, Kornauth C, Capper D, Berghoff AS, Asari R, Niederle B, von Deimling A, Birner P \& Preusser M 2012 Immunohistochemical detection of the BRAF V600E-mutated protein in papillary thyroid carcinoma. American Journal of Surgical Pathology 36 844-850. (doi:10.1097/PAS.0b013e318246b527)

Lee JH, Lee ES \& Kim YS 2007 Clinicopathologic significance of BRAF V600E mutation in papillary carcinomas of the thyroid: a metaanalysis. Cancer 110 38-46. (doi:10.1002/cncr.22754)

Marotta V, Guerra A, Zatelli MC, Uberti ED, Di Stasi V, Faggiano A, Colao A \& Vitale M 2013 BRAF mutation positive papillary thyroid carcinoma is less advanced when Hashimoto's thyroiditis lymphocytic infiltration is present. Clinical Endocrinology 79 733-738. (doi:10.1111/cen.12194)

Nam JK, Jung CK, Song BJ, Lim DJ, Chae BJ, Lee NS, Park WC, Kim JS, Jung SS \& Bae JS 2012 Is the BRAF(V600E) mutation useful as a predictor of preoperative risk in papillary thyroid cancer? American Journal of Surgery 203 436-441. (doi:10.1016/j.amjsurg.2011.02.013)

Nikiforova MN, Wald AI, Roy S, Durso MB \& Nikiforov YE 2013 Targeted next-generation sequencing panel (ThyroSeq) for detection of mutations in thyroid cancer. Journal of Clinical Endocrinology and Metabolism 98 E1852-E1860. (doi:10.1210/jc.2013-2292)

Nowell PC 1976 The clonal evolution of tumor cell populations. Science 194 23-28. (doi:10.1126/science.959840)

Oler G, Ebina KN, Michaluart P Jr, Kimura ET \& Cerutti J 2005 Investigation of BRAF mutation in a series of papillary thyroid carcinoma and matched-lymph node metastasis reveals a new mutation in metastasis. Clinical Endocrinology 62 509-511. (doi:10.1111/j.1365-2265.2005. 02235.x)

Paulson L, Shindo M, Schuff K \& Corless C 2012 The role of molecular markers and tumor histological type in central lymph node metastasis 
of papillary thyroid carcinoma. Archives of Otolaryngology-Head \& Neck Surgery 138 44-49. (doi:10.1001/archoto.2011.226)

Ricarte-Filho JC, Ryder M, Chitale DA, Rivera M, Heguy A, Ladanyi M, Janakiraman M, Solit D, Knauf JA, Tuttle RM et al. 2009 Mutational profile of advanced primary and metastatic radioactive iodinerefractory thyroid cancers reveals distinct pathogenetic roles for BRAF, PIK3CA, and AKT1. Cancer Research 69 4885-4893. (doi:10.1158/ 0008-5472.CAN-09-0727)

Sargent R, LiVolsi V, Murphy J, Mantha G \& Hunt JL 2006 BRAF mutation is unusual in chronic lymphocytic thyroiditis-associated papillary thyroid carcinomas and absent in non-neoplastic nuclear atypia of thyroiditis. Endocrine Pathology 17 235-241. (doi:10.1385/EP:17:3:235)

Sassolas G, Hafdi-Nejjari Z, Ferraro A, Decaussin-Petrucci M, Rousset B, Borson-Chazot F, Borbone E, Berger N \& Fusco A 2012 Oncogenic alterations in papillary thyroid cancers of young patients. Thyroid $\mathbf{2 2}$ 17-26. (doi:10.1089/thy.2011.0215)

Seol H, Lee HJ, Choi Y, Lee HE, Kim YJ, Kim JH, Kang E, Kim SW \& Park SY 2012 Intratumoral heterogeneity of HER2 gene amplification in breast cancer: its clinicopathological significance. Modern Pathology 25 938-948. (doi:10.1038/modpathol.2012.36)

Taniguchi K, Okami J, Kodama K, Higashiyama M \& Kato K 2008 Intratumor heterogeneity of epidermal growth factor receptor mutations in lung cancer and its correlation to the response to gefitinib. Cancer Science 99 929-935. (doi:10.1111/j.1349-7006.2008. 00782.x)

Trovisco V, Soares P, Preto A, de Castro IV, Lima J, Castro P, Maximo V, Botelho T, Moreira S, Meireles AM et al. 2005 Type and prevalence of BRAF mutations are closely associated with papillary thyroid carcinoma histotype and patients' age but not with tumour aggressiveness. Virchows Archiv 446 589-595. (doi:10.1007/s00428-005-1236-0)

Unger K, Zitzelsberger H, Salvatore G, Santoro M, Bogdanova T, Braselmann H, Kastner P, Zurnadzhy L, Tronko N, Hutzler P et al. 2004 Heterogeneity in the distribution of RET/PTC rearrangements within individual post-Chernobyl papillary thyroid carcinomas. Journal of Clinical Endocrinology and Metabolism 89 4272-4279. (doi:10.1210/ jc.2003-031870)

Vasko V, Hu S, Wu G, Xing JC, Larin A, Savchenko V, Trink B \& Xing M 2005 High prevalence and possible de novo formation of BRAF mutation in metastasized papillary thyroid cancer in lymph nodes. Journal of Clinical Endocrinology and Metabolism 90 5265-5269. (doi:10.1210/jc.2004-2353)

Xing M, Alzahrani AS, Carson KA, Viola D, Elisei R, Bendlova B, Yip L, Mian C, Vianello F, Tuttle RM et al. 2013 Association between BRAF V600E mutation and mortality in patients with papillary thyroid cancer. Journal of the American Medical Association 309 1493-1501. (doi:10.1001/jama.2013.3190)

Received in final form 25 September 2014

Accepted 29 September 2014

Made available online as an Accepted Preprint

29 September 2014
(C) 2014 Society for Endocrinology Printed in Great Britain
Published by Bioscientifica Ltd. 